\title{
Deleterious outcome of No-React-treated stentless valved conduits after aortic root replacement: Why were Warnings ignored?
}

Thierry P. Carrel, MD, Florian S. Schoenhoff, MD, Juerg Schmidli, MD, Mario Stalder, MD, Friedrich S. Eckstein, MD, and Lars Englberger, MD

From the Department of Cardiovascular Surgery, University Hospital, Berne, Switzerland.

The Shelhigh NR-2000C is a totally biologic stentless conduit designed for the treatment of various aortic root pathologies. After implanting 115 conduits, 7 patients presented with disastrous findings, including aortic root rupture. Meticulous follow-up of those patients who already underwent implantation of this device has to be recommended.

Thierry Carrel reports terminating a previous relationship with Shelhigh.

Received for publication Aug 22, 2007; accepted for publication Sept 11, 2007.

Address for reprints: Thierry P. Carrel, MD, Department of Cardiovascular Surgery, University Hospital, CH-3010 Berne, Switzerland (E-mail: thierry.carrel@insel.ch).

J Thorac Cardiovasc Surg 2008;136:52-7

$0022-5223 / \$ 34.00$

Copyright $(2008$ by The American Association for Thoracic Surgery

doi:10.1016/j.jtcvs.2007.09.047
Objective: The implantation of a composite graft is the treatment of choice for patients with aortic root disease if the valve cannot be preserved and the patient is not a suitable candidate for a Ross procedure. Several years ago, the Shelhigh NR-2000C (Shelhigh, Inc, Millburn, NJ) was introduced in Europe. Being a totally biologic conduit and considering the lack of homografts, the graft seemed an ideal conduit for patients with destructive endocarditis, as well as for older patients who were not suitable candidates for oral anticoagulation.

Methods: From 2001 until 2006, the Shelhigh NR-2000C stentless valved conduit was implanted in 115 patients for various aortic root pathologies. The conduit consists of a bovine pericardial straight graft with an incorporated porcine stentless valve. Aortic root repair was performed during standard cardiopulmonary bypass and mild hypothermia in the majority of patients. Deep hypothermic circulatory arrest combined with selective antegrade cerebral perfusion was used when the repair extended into the arch.

Results: Seven patients with uncomplicated early outcome presented with unexpected sudden disastrous findings at the level of the aortic root, although 1-year follow-up computed tomographic scans were normal. Four of these patients underwent emergency operations because of desintegration of the graft, along with rupture of the aortic root. Retrospectively, the main findings were persistent fever or subfebrility over months and a halo-like enhancement on computed tomographic scans. Extensive microbiologic examinations were performed without finding a causative organism.

Conclusion: The use of the Shelhigh aortic stentless conduit can no longer be advocated, and meticulous follow-up of patients in whom this device has been implanted has to be recommended.

$\mathrm{T}$ The implantation of a composite graft is the treatment of choice for patients with aortic root disease when the valve cannot be repaired or reimplanted by using the David procedure and when the patient is not a suitable candidate for a pulmonary autograft procedure. ${ }^{1-4}$ Several years ago, a new xenopericardial conduit (Shelhigh, Inc, Millburn, NJ) was introduced in Europe. ${ }^{5,6}$ The Shelhigh conduit NR-2000C consists of a bovine pericardial straight graft with an incorporated porcine stentless valve. It is preserved in a special process, called No-React by the manufacturer, meaning it is glutaraldehyde cross-linked, detoxified, and heparin treated with the aim of less calcification and tissue deterioration in the long term. ${ }^{7-9}$ We present here some alarming, if not deleterious, signs of conduit malfunction that required reoperation or were most probably responsible for the patient's death.

\section{Materials and Methods}

\section{Patients}

The Shelhigh stentless valved conduit was implanted in 115 patients between 2001 and March 2006 for various aortic root pathologies. The initial clinical experience was satisfactory; in 


\section{Abbreviations and Acronyms}

$\mathrm{CT}=$ computed tomography

$\mathrm{FDA}=$ US Food and Drug Administration

particular, hemostatic and hemodynamic properties were encouraging. Being a totally biologic conduit and considering the lack of homografts, the Shelhigh graft seemed an ideal conduit for patients with destructive endocarditis, as well as for older patients who do not want lifelong oral anticoagulation. ${ }^{10-13}$

\section{Device}

The Shelhigh stentless aortic valve conduit is a totally biologic conduit available in sizes between 21 and $31 \mathrm{~mm}$. Rinsing is not required. The conduit and the valve are glutaraldehyde cross-linked, detoxified, and heparin treated with No-react. This proprietary detoxification process eliminates residual glutaraldehyde and ensures stable tissue cross-linking with less calcification and tissue deterioration in the long term. ${ }^{7-9}$ After achieving preservation, individual noncoronary porcine cusps are selected and fitted on a scallopshaped tubular bovine pericardium. This assembly satisfies the hemodynamic requirements for flexibility and strength. The $150-\mathrm{mm}-$ long pericardial cuff can be trimmed appropriately for each case and facilitates repair when complete repair of the ascending aorta is required. In vitro hemodynamics have been described as excellent, with ideal coaptation of the leaflets. Laboratory testing performed in a pulse duplicator evaluated the stentless valve in the fresh aortic root; at all flow rates, the stentless valve showed uniformly higher effective orifice areas and better hemodynamics than the similar valve with a ring. These tests confirmed that the ring transfers the stress from the commissures to the aortic valve. ${ }^{14,15}$

\section{Surgical Technique}

Aortic root repair is performed during standard cardiopulmonary bypass and mild hypothermia in the majority of patients. Deep hypothermic circulatory arrest combined with selective antegrade cerebral perfusion is used when the repair extends into the aortic arch. The diseased aortic root and ascending aorta are completely removed, and the coronary ostia are excised with a small rim of surrounding aortic tissue. After sizing the aortic anulus with Shelhigh sizers, a valved conduit 1 or 2 sizes larger is implanted. The proximal annulus anastomosis is performed by using either continuous 4-0 polypropylene sutures or interrupted mattress 2-0 Ethibond sutures (Ethicon, Somerville, NJ). The coronary ostia are reimplanted into the conduit by using the button technique with 5-0 or 6-0 running monofilament sutures. Finally, the distal anastomosis is performed with 4-0 running polypropylene sutures (Figures 1 and 2).

\section{Results}

\section{Postoperative Course}

Unfortunately, there has been increasing concern about deleterious midterm outcomes in several patients in our singlecenter experience. We present 7 patients with uncomplicated early outcomes after aortic root replacement: 4 of them presented with unexpected sudden disastrous findings at the

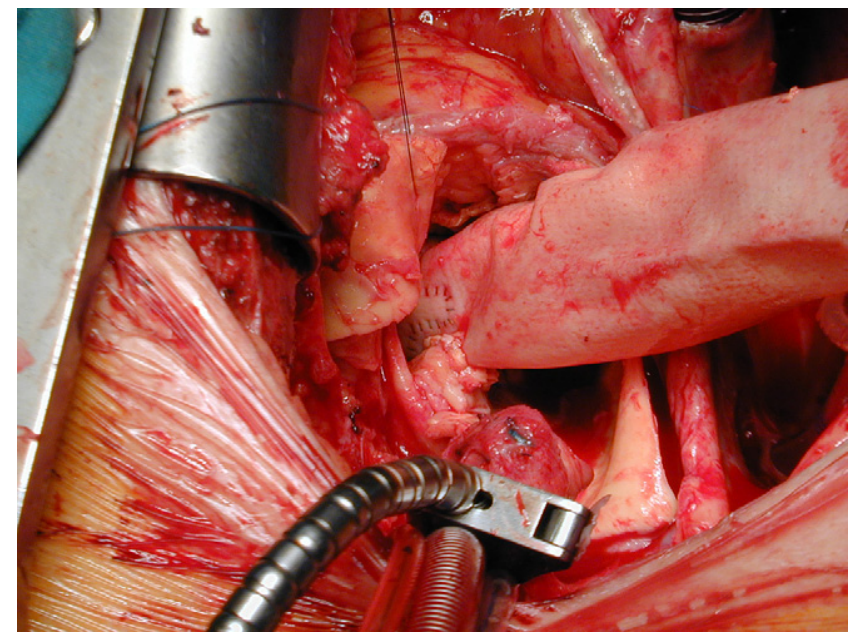

Figure 1. Implantation sequence of the Shelhigh conduit in a complex redo case. Left coronary is re-implanted (With permission of $\mathbf{J}$ Heart Valve Dis).

level of the aortic root, although the 1-year follow-up computed tomographic (CT) scans were normal. These 4 patients underwent conduit exchange because of desintegration of either proximal or coronary anastomoses. The main findings were persistent fever or subfebrile condition for months and a halo-like enhancement around the conduit on CT scans.

Because we first suspected severe infective endocarditis of the graft extensive testing and evaluation of the graft material and patient's blood was performed. Considering the utterly strange intraoperative findings and the nature of the graft, we even considered bovine microorganisms, without finding a causative organism. None of these patients underwent primary implantation of the graft because of native valve endocarditis.

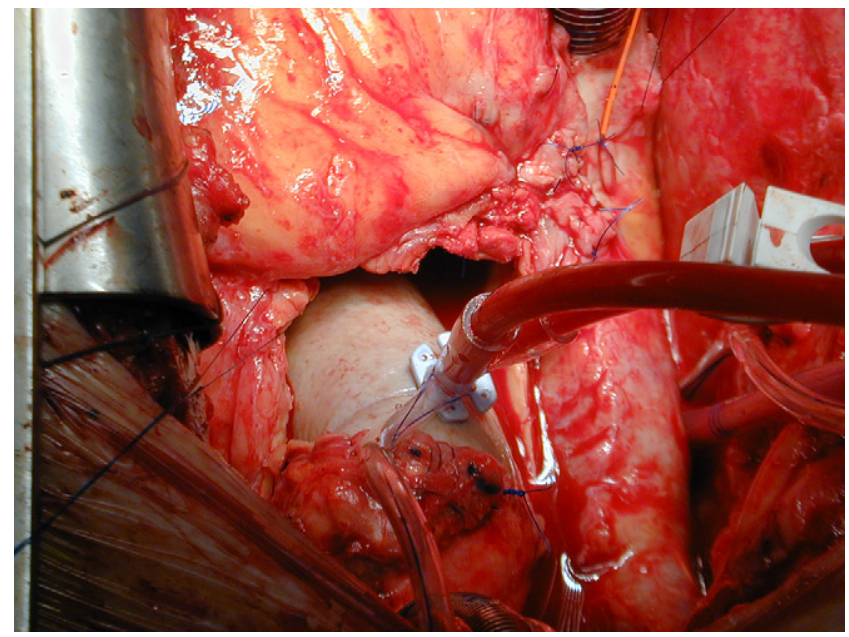

Figure 2. Final view of the Shelhigh conduit in a complex redo case, following distal anastomosis (With permission of $\mathbf{J}$ Heart Valve Dis). 
Patient 1 underwent implantation of a Shelhigh composite graft because of annuloaortic ectasia with aortic valve insufficiency. One year later, emergency reoperation was necessary because of rapid deterioration of the general condition and severe dyspnea of New York Heart Association functional class IV. CT scans showed a completely destroyed aortic root and suspicion of ventriculoaortic disconnection. The intraoperative findings confirmed these previous findings and showed complete destruction of the aortic root; the proximal anastomosis, which had been performed with interrupted, pledget-reinforced sutures, was ruptured, as well as both coronary anastomoses (Figure 3) 3 months before CT was completely normal in this patient (Figure 4). A brownish gelatinous material was found at the level of the remnants of the native annulus. Because we were suspecting a fulminant endocarditis and because the implantation of a new aortic root prosthesis required intraventricular sutures, we implanted a new Shelhigh composite graft. The patient made an uneventful recovery and died 5 months later of aortic rupture, despite a normal 3-month follow-up CT scan.

Patient 2 presented with high transvalvular gradient but normal leaflet motion 1 year after implantation of a Shelhigh stentless valve because of aortic valve stenosis. Re-exploration showed a partial destruction of the aortic root, which had not been seen before. The aortic root had to be replaced, and we used a Shelhigh conduit. One year later, the patient presented with severe dyspnea. Echocardiography showed moderate aortic insufficiency, severe mitral valve regurgitation, and aortic root rupture at the level of the right coronary sinus. Emergency reoperation showed a huge false aneurysm with destruction of the aortomitral continuity, whereas the right coronary artery ostium and the distal graft to the native aortic anastomosis were completely dehiscent. A second attempt to replace the destroyed aortic root was not successful,

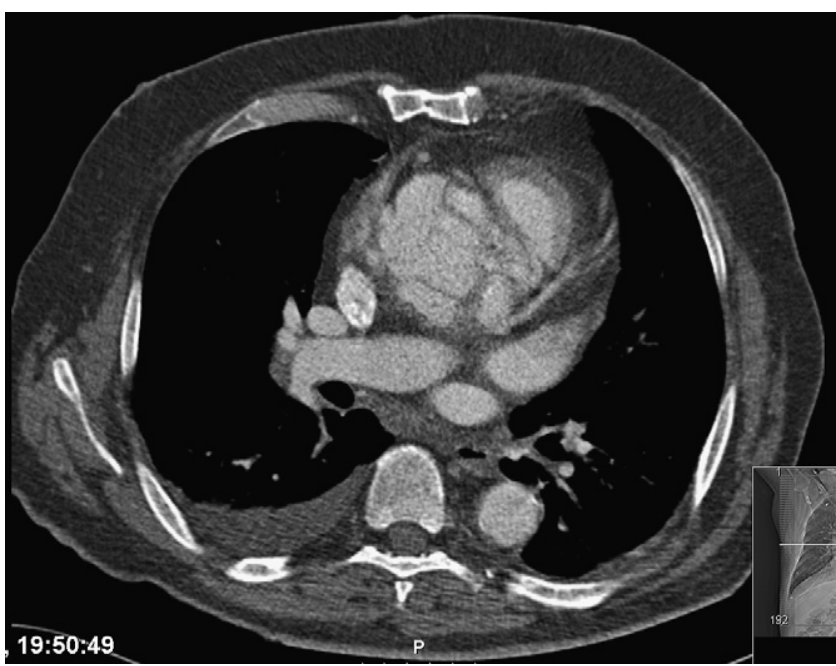

Figure 3. Complete destruction of the aortic root 1 year after conduit implantation because of annuloaortic ectasia.

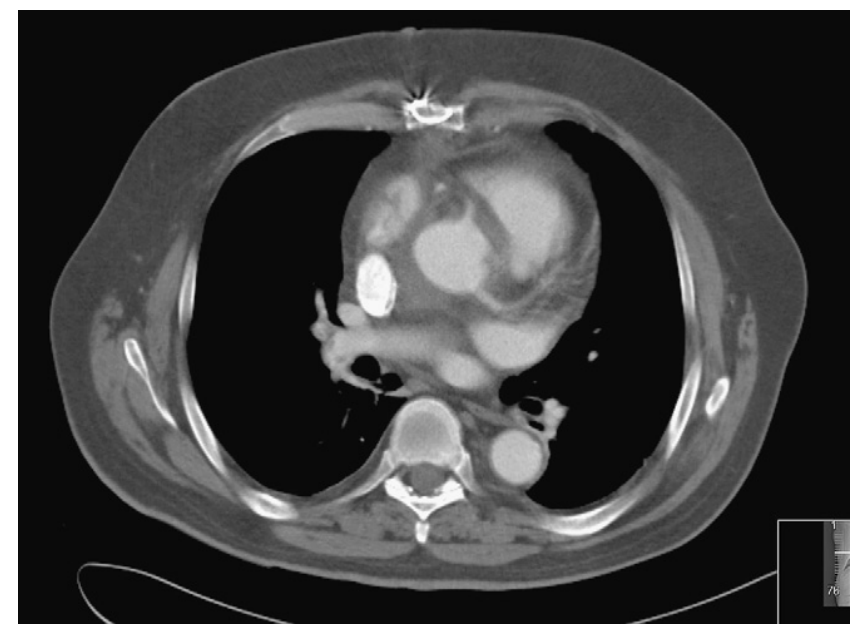

Figure 4. Same patient as in Fig 3 with normal CT scan 3 months before.

and the patient could not be weaned from cardiopulmonary bypass. She died in the operating theater after hours of reconstructive surgery.

Patient 3 underwent composite graft implantation because of annuloaortic ectasia with a bicuspid aortic valve. Because subfebrile temperature persisted for weeks after the operation, a close follow-up was performed. Two years later, a pseudoaneurysm of the aortic root was suspected. Re-exploration showed impressive destruction of the pericardial tube, dehiscent sutures of the coronary arteries, and a perfused pseudoaneurysm, representing a contained rupture at the level of the aortic annulus (Figures 5-8). In this case, too, a lot of brownish material was found close to the stentless valve tube, but no microorganisms could be detected in serial microbiologic examinations. An aortic homograft was

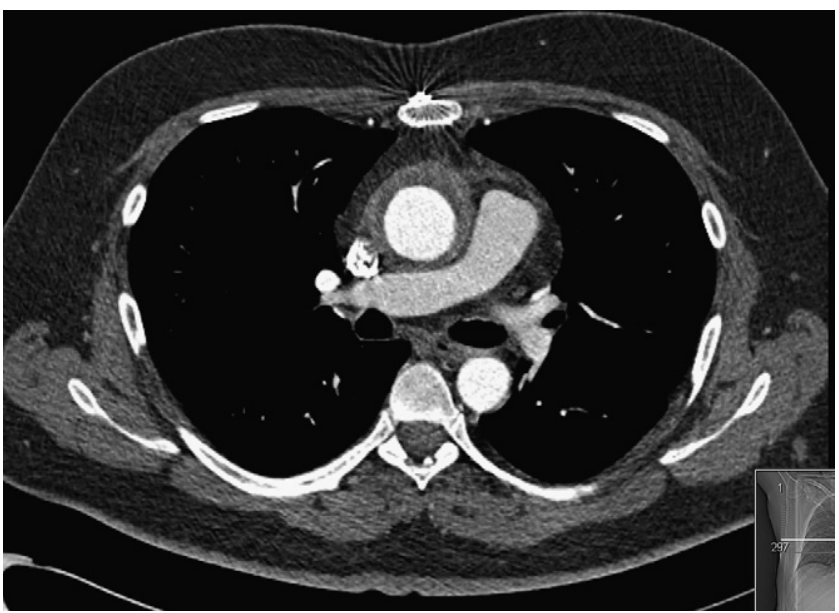

Figure 5. Follow-up computed tomographic scan of patient 3 with periaortic reaction, but no sign of disfunction of the conduit. 


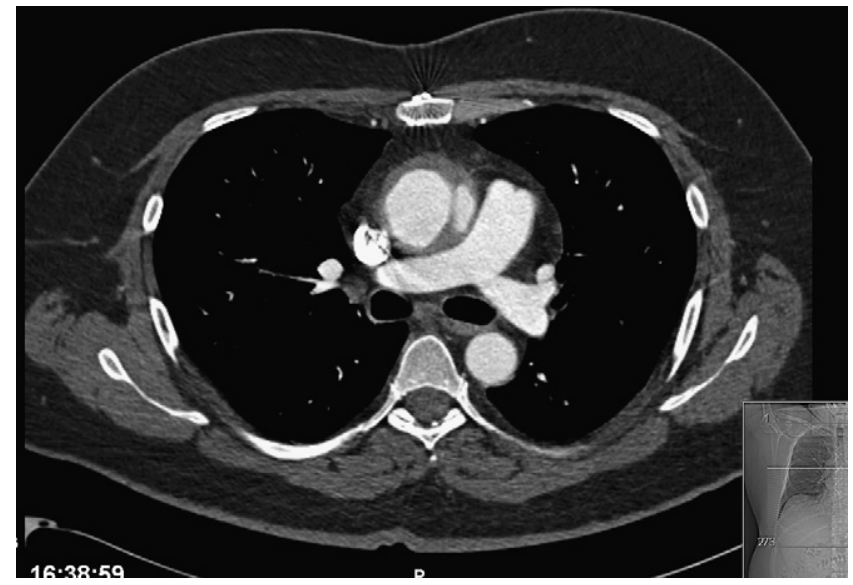

Figure 6. Computed tomographic scan of patient 3 one year later with perfused pseudoaneurysm of the aortic root.

implanted into the left ventricular outflow tract, and reimplantation of the coronary ostia had to be performed by using saphenous vein graft interposition because the coronary buttons were completely necrotic.

Patient 4 presented with aortic root dilation, severe aortic valve regurgitation, and dilation of the aortic arch. She underwent implantation of a Shelhigh composite graft with replacement of the ascending aorta, as well the arch, with a prosthetic aortic graft. CT scanning and echocardiographic analysis performed 6 months later showed normal postoperative conditions. (Figure 9) Right before the 1-year follow-up the patient presented with fever for weeks. Another CT scan

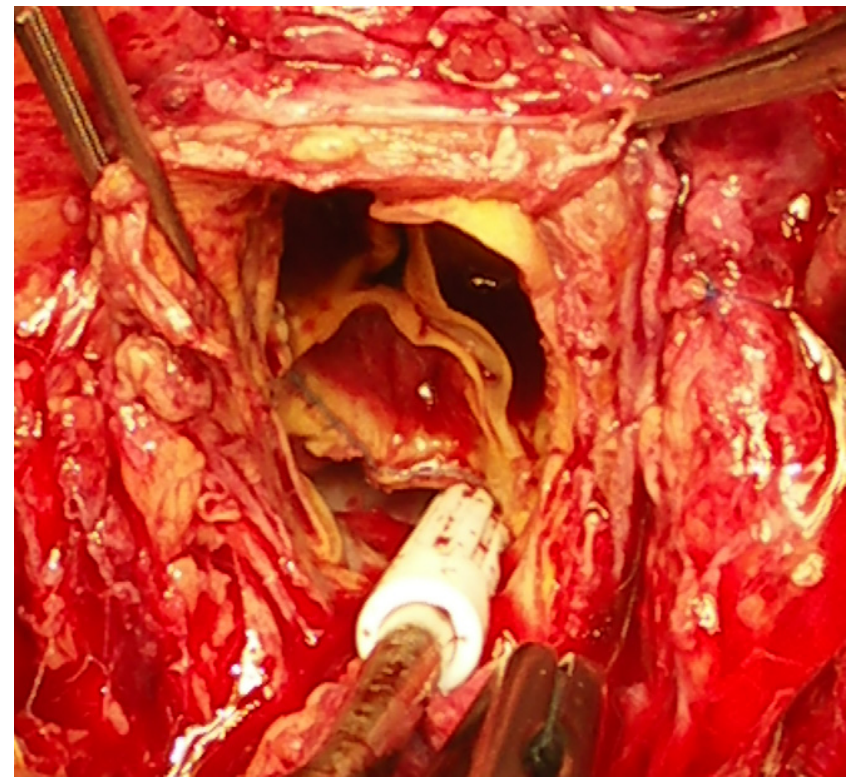

Figure 7. Intraoperative view of destroyed aortic root and dissolved conduit in patient 3 .

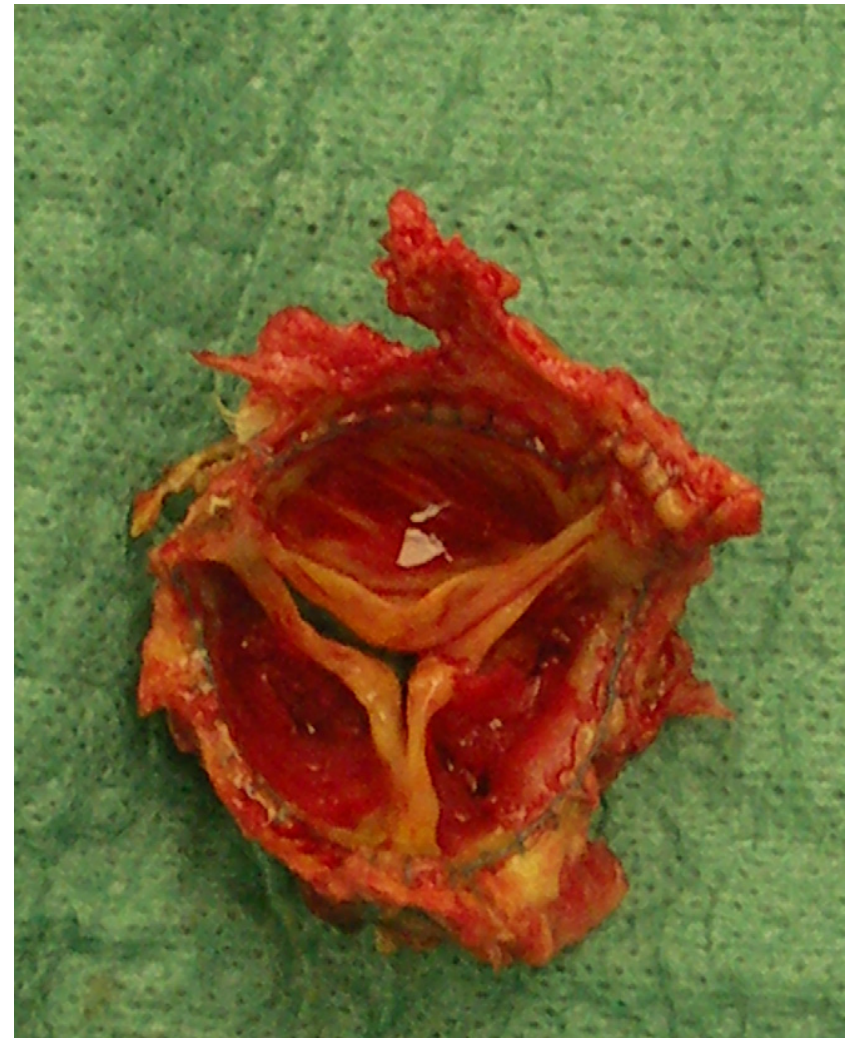

Figure 8. The valve was normal in patient 3 but the conduit completely dissolved.

was performed and showed enhancement around the proximal anastomosis and a impressive halo-like appearance (Figure 10). One week later, re-exploration was performed

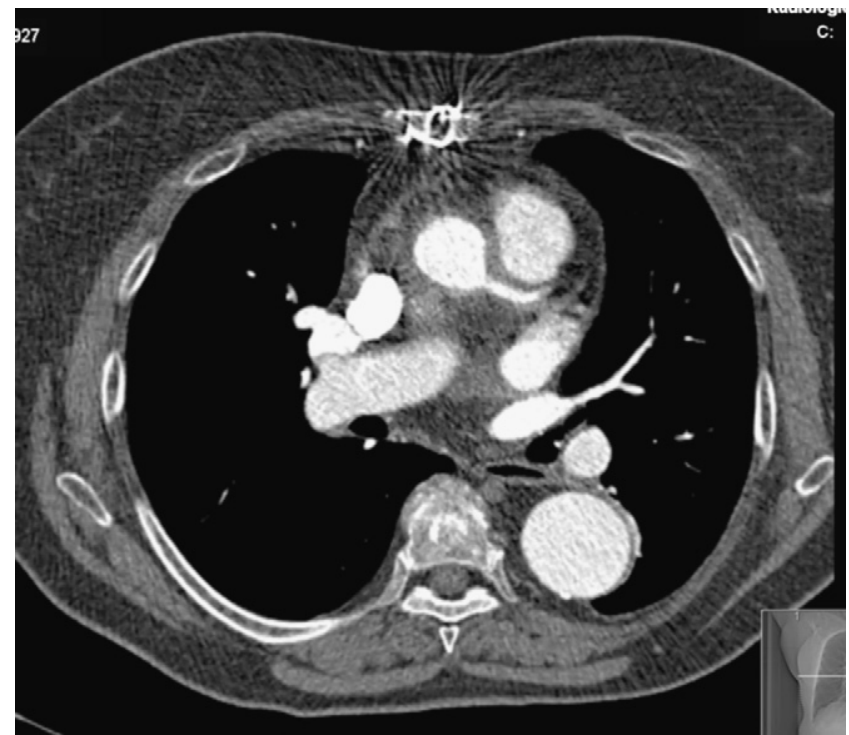

Figure 9. CT scan of patient 4, 6 months postoperatively. 


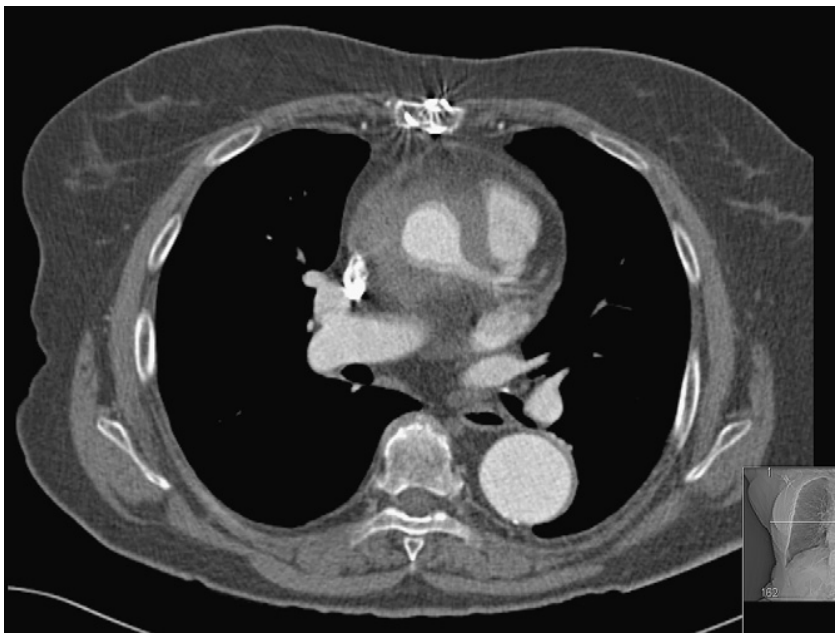

Figure 10. CT scan of patient 4, 6 months after figure 9 shows increasing peri-aortic reaction.

because of deterioration and a leakage was demonstrated at the level of the proximal aortic annular anastomosis. Re-exploration showed a completely necrotic annulus. The root was reconstructed by using a homograft and a saphenous vein graft for interposition to the left coronary artery.

We have to claim 3 unexplained deaths in 3 additional patients (patients 5-7) in the first 2 years after implantation of a Shelhigh stentless tube valved graft. Review of the follow-up CT scans showed a halo-like enhancement at the level of the root in every patient. Necropsy was performed in 1 patient and demonstrated findings very similar to those found in the reoperated patient. One patient was referred with a rupture at the level of the aortic root with a huge hematoma extending into the arch but was no longer a surgical candidate because of advanced age. He was transferred to another hospital and died a few days later, most probably from aortic root rupture.

\section{Discussion}

Several technical options can be used to repair or replace the aortic root. In addition to aortic valve-sparing techniques, composite grafts, including a mechanical valve and, more rarely, the pulmonary autograft, are the most commonly used material for this purpose. ${ }^{1-4}$ Traditional glutaraldehyde-treated valves tend to calcify, especially in younger patients. The No-React detoxification process eliminates residual glutaraldehyde and ensures stable tissue cross-linking. In vitro results on reducing calcification and tissue deterioration have been encouraging. ${ }^{7,8}$ There has been limited published clinical experience with this new valved conduit so far. Preliminary reports showed satisfactory results, especially when the conduit was implanted because of destructive aortic valve endocarditis. ${ }^{14}$ The stentless valved tube graft demonstrated similar results as cryopreserved homografts in terms of ease of implantation, perioperative mortality, cure of infection, and hemodynamic characteristics.

Our first experience confirmed that the Shelhigh stentless valved conduit was easy to handle and showed excellent early hemodynamic characteristics. The material was highly hemostatic because there was no bleeding from stitches through the pericardial tissue. There are no fabric or mechanical components that would make this conduit ideal for the treatment of the infected aortic root when homografts are not available. The pericardial tube allows for nearly unlimited distal aortic repair. In older patients this conduit was thought to be an excellent alternative to a composite graft with a mechanical valve because long-term anticoagulation is not required.

However, despite our favorable initial evaluation of this biologic conduit, we observed some deleterious findings in several patients during short-term and midterm follow-up that forced us to interrupt further use of this device. We had repetitive correspondence with the chief scientific officer of the company, but he was not able to provide us with substantial information regarding our observations. ${ }^{16}$ Moreover, he suspected endocarditis of the conduit or technical failure during initial implantation, which would have resulted in pseudoaneurysm formation. Because no patients had positive blood culture results and the first postoperative CT scans 3 to 6 months following surgery were normal, we could not accept these reasons to explain the observed problems.

The company assured us that there was no report on similar events thus far. For this reason, we were hesitant to undertake steps in terms of a formal report and considered endocarditis as the most likely cause. Some time later, we fortunately discovered that 2 warning letters had already been issued by the US Food and Drug Administration (FDA) in 2000 and 2003 complaining about the manufacturing standards of the company. ${ }^{17,18}$

On April 19, 2007, the FDA published a preliminary public health notification on possible contamination and malfunction of devices manufactured by Shelhigh, Inc. A few days later, the FDA seized all medical products from the device manufacturer for significant violations because the company declined the voluntary recall recommended by the FDA. ${ }^{19}$

Since then, we stopped using Shelhigh products and are expecting additional information about this unclear and unsatisfying situation. In the meantime, we cannot advocate the use of the Shelhigh aortic stentless conduit and recommend meticulous clinical and imaging follow-up of patients in whom this device has been implanted.

\section{References}

1. Kouchoukos NT. Composite graft replacement of the ascending aorta and aortic valve with the inclusion-wrap technique and open technique. Semin Thorac Cardiovasc Surg. 1991;3:171-6.

2. Yacoub MH, Gehle P, Chandrasekaran V, Birks E, Child A, RadleySmith R. Late results of a valve-preserving operation in patients with 
aneurysms of the ascending aorta and root. J Thorac Cardiovasc Surg. 1998;115:1080-90.

3. David TE, Armstrong S, Ivanov J, Feindel C, Omran A, Webb G. Results of aortic valve-sparing operations. J Thorac Cardiovasc Surg. 2001;122:39-46.

4. Kouchoukos NT. Aortic allograft and pulmonary autografts for replacement of the aortic valve and aortic root. Ann Thorac Surg. 1999;67: 1846-8.

5. Carrel TP, Berdat P, Englberger L, Eckstein F, Immer F, Seiler C, et al. Aortic root replacement with a new stentless aortic valve xenograft conduit: preliminary hemodynamic and clinical results. $J$ Heart Valve Dis. 2003;12:752-7.

6. Siniawski H, Lehmkuhl H, Weng Y, Pasic M, Yankah C, Hoffmann M, et al. Stentless aortic valves as an alternative to homografts for valve replacement in active infective endocarditis complicated by ring abscess. Ann Thorac Surg. 2003;75:803-8.

7. Albolhoda A, Yu S, Oyarzun J, McCormick J, Han S, Kemp F, et al. No-React detoxification process: a superior anticalcification method for bioprostheses. Ann Thorac Surg. 1996;62:1724-30.

8. Albolhoda A, Sumei Y, Oyarzun J, McCormick J, Bogden J, Gabbay S. Calcification of bovine pericardium glutaraldehyde versus No-React biomodification. Ann Thorac Surg. 1996;62:169-74.

9. CE 0318 technical report. The NR-2000C stentless aortic valve conduit: a breakthrough in bioprosthetic design. Millburn (NJ): Shelhigh, Inc; USA.

10. Siniawski H, Lehmkuhl H, Wenig Y, Pasic M, Yankah C, Hoffmann M, et al. Stentless aortic valves as an alternative to homografts for valve replacement in active infective endocarditis complicated by ring abscess. Ann Thorac Surg. 2003;75:803-8.
11. Akar AR, Szafranek A, Alexiou C, Janas R, Jasinski MJ, Swanevelder J, et al. Use of stentless xenografts in the aortic position: determinants of early and late outcome. Ann Thorac Surg. 2002;74:1450-8.

12. Dearani JA, Orszulak TA, Schaff HV, Daly RC, Anderson BJ, Danielson GK. Results of allograft aortic valve replacement for complex endocarditis. J Thorac Cardiovasc Surg. 1997;113:285-91.

13. Grandmougin D, Prat A, Fayad G, Decoene C, Pol A, Waremboug H. Acute aortic endocarditis with annular destruction: assessment of surgical treatment with cryopreserved valvular homografts. J Heart Valve Dis. 1999;8:234-41.

14. Marianeschi SM, Iacona GM, Seddio F, Abella RF, Condoluci C, Cipriani A, et al. The Shelhigh No-React porcine pulmonary valve conduit: a new alternative to the homograft. Ann Thorac Surg. 2001;71:619-23.

15. Beck A, Thubrikar MJ, Robicsek F. Stress analysis of the aortic valve with and without the sinuses of Valsalva. J Heart Valve Dis. 2001;10:1-11.

16. Campbell EG, Gruen RL, Mountford J, Miller LG, Cleary PD, Blumenthal D. A national survey of physician-industry relationship. N Engl J Med. 2007;356:1742-50.

17. Available at: http://www.fda.gov/foi/warning_letters/archive/m3695n. pdf. Accessed Aug 22, 2007.

18. Available at: http://www.fda.gov/foi/warning_letters/archive/g5674d. pdf. Accessed Aug 22, 2007.

19. FDA preliminary public health notification: possible contamination and malfunction of heart valves and valved conduits, annuloplasty rings, surgical grafts, meshes and other devices manufactured by Shelhigh, Inc. April 18, 2007. Available at: www.fda.gov/cdrh/safety/041807shelhigh.html. Accessed Aug 22, 2007.

20. Tjan TD, Klotz S, Schmid C, Scheld HH. Creation of a self-made total artificial heart using combined components of available ventricular assist devices. Thorac Cardiovasc Surg. 2008;56:51-3.

\section{Addendum}

Recently, a tricky case was presented by the group of Hans Scheld in Munster. ${ }^{20}$ The paper focused on the creation of a selfmade total artificial heart using different components of available ventricular assist devices following partial resection of the heart. However, the primary problem of this patient was the failure of a Shelhigh aortic valved conduit (Shelhigh Inc, NJ, USA) implanted a few months earlier in the setting of acute type A aortic dissection.

Most probably, the authors were at that time not aware of this rare but disastrous complication which has been encountered by others but unfortunately has not been reported in the literature before. The case reported by Tjan and co-authors have strong similarity to our cases. The aortic stenosis was probably not due to early degeneration of the valve but due to compression of the valve by an extravasation. Fortunately we did not experience any perforation of the root into the right ventricle but this complication fits very well in the spectrum of problems we have observed. The case described by Tjan and colleagues required nearly 6 months of hospitalization, biventricular assist device and finally cardiac transplantation to manage severe problems caused by a deficient implant.

We had repetitive correspondance with the Chief Scientific Officer of the company but no substantial informations regarding our observations were provided. The company still assured us that there was no report on similar events so far. For this reason, we were hesitant to undertake steps in terms of a formal report and considered endocarditis as the most likely cause. 